\title{
ANALISIS KOORDINASI PROTEKSI RELAY ARUS LEBIH PADA SISTEM KELISTRIKAN PT. PETROKIMIA GRESIK PABRIK AMUREA 2 BERBASIS ALGORITMA GENETIKA
}

\author{
Erfan Djati Widodo'), Denny Irawan ${ }^{2)}$, Rini Puji Astutik ${ }^{3)}$ \\ ${ }^{1,2)}$ Jurusan Teknik Elektro, Fakultas Teknik - Universitas Muhammadiyah Gresik \\ 1erfandjatiwidodo@gmail.com, ${ }^{2}$ den2mas@umg.ac.id, ${ }^{3}$ astutik_rpa@umg.ac.id \\ Jl. Sumatra No 101, Gresik 61121, Jawa Timur
}

\begin{abstract}
ABSTRAK
Sistem tenaga listrik tidak pernah lepas dari adanya gangguan, baik gangguan short-circuit, overload, maupun gangguan lainnya. Salah satu pengaman umtuk mengisolir gangguan yg terjadi khususnya di PT. Petrokimia Gresik Pabrik Amurea 2 adalah relay arus lebih. Sistem koordinasi proteksi relay arus lebih akan membandingkan metode perhitungan manual dan metode algoritma genetika guna untuk mengoptimalkan sistem tersebut. Hasil simulasi sistem koordinasi relay arus lebih menggunakan metode perhitungan manual masih terdapat overlapping antara kurva relay 11 $(\operatorname{tap}=1,2 ; \operatorname{td}=3,2)$ dan relay $4(\operatorname{tap}=1,16 ; \operatorname{td}=5,58)$. Hasil penelitian menggunakan metode algoritma genetika mendapatkan hasil tidak terjadi overlapping antara kurva relay $11(\operatorname{tap}=0,9 ; \mathrm{td}=$ 3,2 ) dan relay 4 (tap 1,5; td $=5,7$ ). Dengan hasil tersebut, sistem koordinasi proteksi relay arus lebih optimal menggunakan algoritma genetika daripada perhitungan manual.
\end{abstract}

Kata kunci: sistem koordinasi proteksi, relay arus lebih, algoritma genetika.

\section{ABSTRACK}

The electric power system is never free from disturbances, whether short-circuit, overload, or other disturbances. One of the safeguards to isolate disturbances that occur, especially at PT. Petrokimia Gresik Plant Amurea 2 is an overcurrent relay. The overcurrent relay protection coordination system will compare the manual calculation method and the genetic algorithm method in order to optimize the system. The simulation results of the overcurrent relay coordination system using the manual calculation method are still overlapping between the curves of relay 11 (tap $=1.2 ; t d=3.2)$ and relay 4 (tap $=1.16 ; t d=5.58)$. The results of the study using the genetic algorithm method obtained that there was no overlap between the curves of relay 11 (tap $=0.9 ; t d=3.2)$ and relay 4 (tap 1.5; $t d=5.7)$. With these results, the current relay protection coordination system is more optimal using genetic algorithms rather than manual calculations.

Keywords: protection coordination system, overcurrent relay, genetic algorithm.

\section{PENDAHULUAN}

PT. Petrokimia Gresik merupakan salah satu perusahaan yang berada di bawah naungan pemerintah yang bergerak di bidang agroindustri. Guna mendukung dari program pemerintah dalam menjaga ketahanan pangan nasional PT. Petrokimia Gresik akhirnya mengambil langkah untuk membangun pabrik baru yaitu Amurea 2 guna meningkatkan kapasitas produksinya, yang 
diharapkan dapat memenuhi kebutuhan pasar terutama di bidang pertanian dan menjadi solusi agroindustri [1]. Pembangunan Pabrik Amurea 2 yang baru dibutuhkan juga sistem tenaga listrik yang handal dan mampu untuk menunjang proses produksi yang ada di dalam pabrik tersebut. Dengan adanya penambahan pabrik Amurea 2 dan pembangkit GGCP (Gresik Gas Cogeneration Plant), maka seperti pada umumnya sistem tenaga listrik tidak pernah lepas dari adanya gangguan pada sistem tenaga listrik. Untuk meminimalisir terjadinya dampak akibat dari gangguan tersebut, maka diperlukan suatu koordinasi proteksi agar keandalan dan kontinuitas pendistribusian sistem tenaga listrik menjadi lebih handal.

Sistem koordinasi proteksi yang digunakan di dunia industri terutama di PT. Petrokimia Gresik adalah menggunakan relay arus lebih (Over Current Relay). Relay arus lebih di desain untuk dapat berkoordinasi dengan relay yang lainnya yang nantinya dapat membuat suatu sistem koordinasi proteksi yang handal untuk menyeleksi dan memilah - milah gangguan yang terjadi. Parameter yang yang di setting pada relay tersebut adalah Arus Pickup (Ipu) dan Time Dial Setting (TDS). Sistem koordinasi proteksi tersebut dapat di simulasikan menggunakan software ETAP 12.6 dengan menggunakan menu "Star Device
Coordination" untuk melihat karakteristik dari sistem proteksi tersebut. Unjuk kerja dari sistem proteksi tersebut dapat dianalisa berdasarkan kurva karakteristik yaitu Time Current Curve (TCC) yang nantinya disesuaikan dan dianalisa sesuai standar Coordination Time Interval (CTI). Namun pada kenyataannya, setting output parameter dari relay arus lebih masih dianggap kurang efektif karena proses perhitungan secara manual dan TCC yang dihasilkan belum sesuai dengan standar CTI.

Metode yang digunakan dalam penelitian ini menggunakan algoritma genetika untuk menentukan setting yang optimal dimana metode pencariannya berdasarkan prinsip proses biologi yaitu evolusi alam. Algoritma ini masuk dalam kelompok algoritma evolusioner dengan menggunakan pendekatan evolusi Darwin di bidang Biologi seperti pewarisan sifat, seleksi alam, mutasi gen dan kombinasi (crossover). Algoritma genetika ini merupakan teknik pencarian optimal dalam bidang ilmu komputer, maka algoritma ini juga termasuk dalam kelompok algoritma metaheuristik [2].

\section{DASAR TEORI}

\subsection{Sistem Tenaga Listrik}

Sistem tenaga listrik secara umum terdiri dari unit-unit pembangkit yang terhubung dengan saluran untuk melayani beban. Semakin berkembang sistem tenaga 
listrik dapat mengakibatkan lemahnya performansi sistem ketika mengalami gangguan. Salah satu efek gangguan adalah osilasi elektromekanik yang jika tidak diredam dengan baik maka sistem akan terganggu dan dapat keluar dari area kestabilannya sehingga mengakibatkan pengaruh yang lebih buruk seperti pemadaman total (black out) [2].

\subsection{Gangguan Sistem Tenaga Listrik}

Gangguan pada sistem tenaga listrik adalah kondisi abnormal yang melibatkan kegagalan peralatan sistem tenaga listrik yang beroperasi pada salah satu tegangan di dalam sistem. Secara umum, dua jenis gangguan yang dapat terjadi. Pertama adalah kegagalan isolasi yang menghasilkan terjadinya hubung singkat dan dapat terjadi sebagai akibat dari kejenuhan dan degradari isolasi dari waktu ke waktu karena kondisi tegangan berlebih yang secara tiba-tiba, kedua adalah kegagalan yang menjadikan berhentinya aliran arus pada suatu sistem [3]. Pada umumnya terdapat beberapa gangguan yang menyebabkan arus berlebih yang mengalir pada sistem tersebut seperti beban lebih (overload), hubung singkat (short circuit), dan tegangan lebih (over voltage) [4].

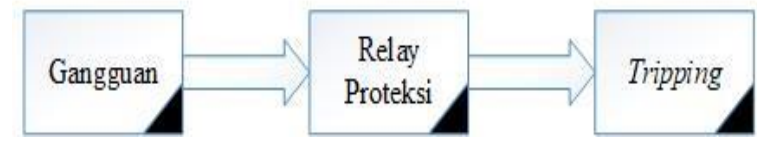

Gambar 1 Sistem Kerja Relay Proteksi

\subsection{Sistem Proteksi Tenaga Listrik}

\section{Relay Sebagai Proteksi}

Relay merupakan sebuah peralatan pada sistem tenaga listrik yang berfungsi untuk men-trigger $\mathrm{CB}$ untuk memutus sumber aliran listrik ketika terjadi gangguan. Sehingga gangguan tersebut tidak menjalar ke sistem dan perlatan yang berada di sekitarnya. Flowchart sistem kerja relay sebagai proteksi seperti pada gambar 1 [5].

\subsection{Relay Arus Lebih (Over Current Relay)}

Relay arus lebih yaitu sebuah relay proteksi yang bekerja apabila terdapat nilai arus yang telah melebihi dari nilai settingnya. Relay jenis ini paling umum digunakan di dunia industry karena hanya ada satu variable yang digunakan yaitu arus [6].

Prinsip kerja dari relay arus lebih yaitu berdasarkan nilai setting arus yang ditetapkan yang biasa dinamakan arus pickup (Ipu). Apabila sisi sekunder dari CT membaca bahwa nilai arus yang melewati CT lebih besar daripada arus pickup maka relay akan memerintahkan $\mathrm{CB}$ untuk memutus aliran tenaga listrik yang melewati daerah proteksi relay tersebut. Pemilihan rasio CT 
sangat penting dalam menentukan range dan nilai setting.

\subsection{Setting Relay Arus Lebih}

Setting relay arus lebih sebagai proteksi sistem tenaga listrik harus sesuai dengan kebutuhan agar fungsi dari sistem proteksi bekerja secara optimal ketika terjadi suatu gangguan dalam sistem tersebut. Hal yang perlu diperhatikan dalam setting relay arus lebih adalah simulasi arus hubung singkat. Dengan mengetahui arus hubung singkat minimum (line to line 30 cycle) dan hubung singkat maksimum ( 3 phase 4 cycle) dapat dijadikan acuan untuk menentukan setting yang tepat [5].

\subsection{Koordinasi Relay Berdasarkan Arus dan Waktu}

Dalam sistem koordinasi proteksi dibutuhkan adanya koordinasi antar relay berdasarkan arus dan waktu [9]. Koordinasi tersebut digunakan untuk menentukan time delay dalam suatu pengaman sistem tenaga listrik [7]. Untuk lebih jelasnya CTI (Coordination Time Interval) dapat dilihat pada tabel 1 [10].

Tabel 1 Clearing Time Relay

\begin{tabular}{|l|c|c|}
\hline \multirow{2}{*}{ Components } & \multicolumn{2}{|c|}{ CTI } \\
\cline { 2 - 3 } & Electromechanical & Static \\
\hline $\begin{array}{l}\text { Circuit Breaker } \\
\text { Opening }\end{array}$ & $0.08 \mathrm{~s}$ & $0.08 \mathrm{~s}$ \\
\hline
\end{tabular}

\begin{tabular}{|l|c|c|}
\hline Relay Overtravel & $0.10 \mathrm{~s}$ & $0 \mathrm{~s}$ \\
\hline $\begin{array}{l}\text { Relay tolerance } \\
\text { error }\end{array}$ & $0.17 \mathrm{~s}$ & $0.17 \mathrm{~s}$ \\
\hline Total CTI & $0.35 \mathrm{~s}$ & 0.24 \\
\hline
\end{tabular}

\subsection{Algoritma Genetika}

Algoritma genetika adalah suatu metode pencarian yang digunakan dengan menggunakan prinsip proses biologi yaitu evolusi alam. Algoritma ini berdasarkan pada suatu proses genetik pada makhluk hidup yaitu perkembangan generasi dari tahap awal sampai tahap akhir. Sehingga prinsip seleksi alam "siapa yang kuat, dia yang bertahan" atau biasa disebut dengan "survive" menjadi filosofi dalam algoritma ini [11]. Berikut pseudocode untuk Algoritma Genetika : 
GenetikAlgorithm(population, Fitness-FN)

-> an individual

\{input berupa population, sebuahkumpulan individual dan Fitness-FN, sebuah fungsi yang mengukur fitnesssuatu individual\} deklarasi

$i, x, y:$ integer

algoritmarepeat

new_population<-empty set

for $i=1$ to size(population) do

$x<-$ RandomSelection(population, Fitness-

$F N)$

$y<-$ RandomSelection(population,Fitness-

FN)

child $<$ Reproduce $(x, y)$

if(smallRandomProbability) then child $<-$ mutate(child)

add child to new_population

population<-new_population until some

individual is fit enough or the time has elapsed

return the best individual in population(based on Fitness-FN)

function Reproduce( $x, y$

parentindividuals)->individual

deklarasi

algoritma

$n<$-length $(x)$

$c<-$ random number from 1 to $n$

return

Append( $\operatorname{substring}(x, 1, c), \operatorname{substring}(y, c+1, n)$

\section{METODOLOGI PENELITIAN}

Pada bab ini berisi tentang tahapan dari metode penelitian yang akan dilakukan untuk menyelesaikan penelitian ini. Dimulai dari studi literatur, pengumpulan data, pemodelan sistem, simulasi load flow dan short circuit, setting sistem koordinasi proteksi algoritma genetika.

\subsection{Studi Literatur}

Seperti ditunjukkan pada gambar 2, pada tahap awal dalam penyusunan penelitian ini dimulai dengan studi

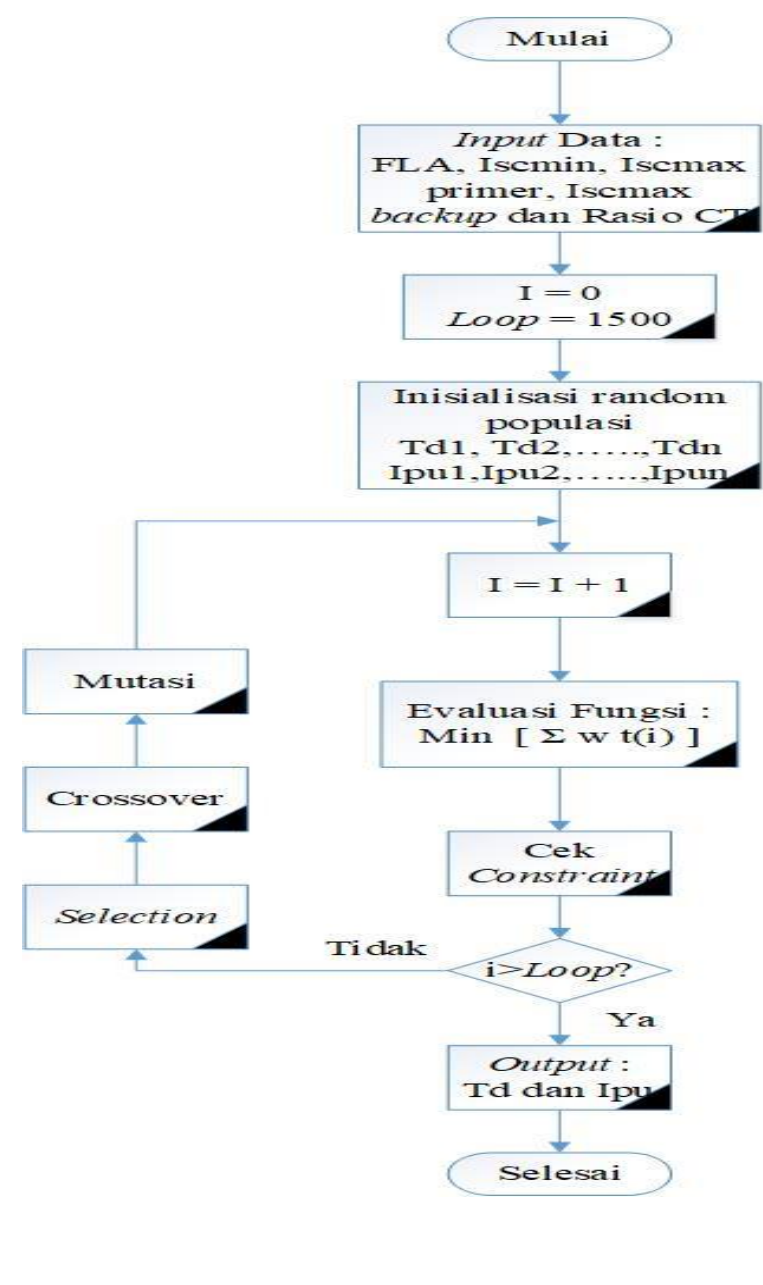

Gambar 2 Flowchart Koordinasi

Proteksi Algoritma Genetika

literatur, yaitu mencari informasi melalui buku-buku, jurnal, artikel, dan internet yang berhubungan dengan elemenelemen yang dipakai. Sumber langsung didapatkan dari hasil diskusi maupun konsultasi dengan orang yang mempunyai kompetensi di bidang ini. 


\subsection{Pengumpulan Data}

Pada tahap ini dilakukan pengumpulan data yang digunakan untuk menyelesaikan penelitian ini. Teknik yang digunakan dalam pengumpulan data yaitu menggunakan metode diskusi secara langsung dan pengambilan dokumen data yang dibutuhkan untuk penelitian ini.

\subsection{Pemodelan Sistem}

Pada tahap ini data yang akan digunakan untuk pemodelan sistem telah terkumpul semua. Data tersebut dapat digunakan untuk memodelkan sistem melalui software ETAP 12.6. Pemodelan sistem yang dimaksud dalam penelitian ini adalah memodelkan sistem dalam bentuk SLD (Single Line Diagram). Pemodelan ini nantinya dapat digunakan untuk simulasi selanjutnya dengan tujuan untuk mendapatkan data yang dibutuhkan untuk setting koordinasi relay proteksi arus lebih.

\subsection{Simulasi Load Flow dan Short - Circuit}

Simulasi load flow adalah suatu simulasi yang berfungsi untuk mengetahui laju aliran daya yang mengalir dari grid sampai ke load. Dari simulasi ini dapat diketahui rating peralatan yang digunakan sesuai dengan standar yang ada. Simulasi load flow juga berfungsi untuk daya aktif dan daya reaktif yang mengalir pada suatu sistem. Selain itu simulasi ini juga dapat digunakan untuk mengetahui losses tegangan dan daya yang berasal dari generator atau grid sampai ke beban.

\subsection{Setting Sistem Koordinasi Proteksi Algoritma Genetika}

Dari gambar 2 dapat dilihat tahapan - tahapan dalam algoritma genetika dalam menentukan solusi sistem koordinasi proteksi relay arus lebih berdasarkan continous genetic algorithm optimization [10].

1. Langkah pertama yang harus dilakukan adalah input data seperti FLA, arus kontribus hubung singkat maksimal dan minimal, rasio CT.

2. Langkah kedua adalah membangkitkan data awal yang berupa nilai Td (Time dial) dan Ipu (arus pickup). Pembangkitan nilai data awal ini dilakukan secara random dengan batasan yang telah ditentukan sebelumnya. Dalam algoritma genetika nilai Td dan Ipu dikelompokkan dalam suatu kromosom dimana jumlah $\mathrm{Td}$ berserta Ipu berjumlah sama dengan jumlah relay yang akan dihitung. Adapun batasan dari nilai Td dan Ipu sering disebut dengan constraint [10].

- $0,9 \leq T d \leq 6$

- $0,5 F L A \leq I p u \leq 2,5$ FLA 
3. Langkah ketiga adalah mengevaluasi nilai hasil random ke dalam fungsi objektif. Pada tiap generasi, kromosom akan melalui proses evaluasi dengan menggunakan alat ukur yang disebut fitness. Nilai fitness suatu kromosom menggambarkan kualitas kromosom dari populasi tersebut. Nilai fitness ditentukan dari nilai fungsi objektif. Fungsi objektif tersebut menunjukkan hasil penjumlahan jarak pada tiap kromosom. Semakin tinggi nilai fitness nya maka akan semakin besar kemungkinan kromosom tersebut untuk terpilih ke generasi berikutnya. Jadi, nilai fungsi objektif berbanding terbalik dengan nilai fitness. Seperti pada persamaan ini [11].

$$
\operatorname{Min}(J)=\sum_{i=1}^{n} w i t i
$$

\section{Dimana :}

$\mathrm{n} \quad=$ jumlah relay

ti = waktu operasi relay saat gangguan

wi $=$ bobot kemungkinan kesalahan setiap zona (bernilai 1)

Tujuan dari persamaan fungsi objektif ini adalah meminimalkan jumlah waktu operasi relay utama. Seperti pada persamaan ini.

$$
\text { Fitness }=\frac{A}{F(x)+\varepsilon}
$$

Dimana :

A $\quad=$ konstanta yang ditentukan

$\mathrm{F}(\mathrm{x}) \quad=$ nilai rataan fungsi objektif

$\mathrm{E}=$ Bilangan kecil atau 0

Nilai rataan fungsi objektif didapatkan melalui persamaan ini.

$$
F(x)=\frac{\operatorname{Min}(J)-n}{\Sigma \operatorname{Min}(J)}
$$

Dimana :

$\mathrm{F}(\mathrm{x}) \quad=$ nilai rataan fungsi objektif

Min ( $\mathrm{J})-\mathrm{n}=$ nilai fungsi objektif kromosom ke - n

$\mathrm{E} \operatorname{Min}(\mathrm{J})=$ Total nilai fungsi objektif

4. Langkah keempat adalah memeriksa nilai - nilai dari hasil evaluasi dengan constraint yang telah ditentukan sebelumnya. Adapun constraint dalam sistem koordinasi proteksi sebagai berikut [10].

a. Selisih waktu kerja relay backup dan primer pada saat gangguan pada bus yang sama disebut CTI dengan nilai 0,2 detik.

b. Waktu minimal untuk operasi relay adalah 0,1 detik.

5. Langkah kelima adalah selection. Pada tahapan ini, setelah didapat hasil fitness dari evaluasi yang telah dilakukan, maka perlu ditentukan peringkat fitness berdasarkan bobot 
dari setiap fitness tersebut dengan menggunakan persamaan sebagai berikut.

$$
P(C n)=\frac{\text { Nkeep }-n+1}{\sum_{i=1}^{\text {Nkeep }} i}
$$

Dimana Nkeep adalah jumlah rangking serta $n$ adalah urutan rangking yang dihitung. Sehingga dalam persamaan tersebut akan dihasilkan angka posisi kemungkinan kromosom berada.

6. Langkah keenam adalah crossover. Adapaun persamaan yang digunakan untuk menentukan kawin silang adalah sebagai berikut.

$$
x n e w=(1-\beta) x m+\beta x d
$$

7. Proses diatas akan berlangsung selama $I>$ Loop, dimana Loop merupakan jumlah iterasi yang telah ditentukan. Sedangkan $i$ merupakan variabel pada setiap iterasi bertambah 1 nilainya. Hasil dari jumlah iterasi diatas disebut dengan generasi.

\section{SIMULASI DAN ANALISA}

\subsection{Data Beban}

Beban yang ada pada pabrik Amurea 2 PT. Petrokimia Gresik terdapat beberapa jenis, mulai dari beban motor, static load, lump load dan motor operated valve. Beban beban tersebut memiliki variasi kapasitas yang ada mulai dari kapasitas kecil sampai besar. Dengan masing - masing rating tegangan yang berbeda mulai dari $0,4 \mathrm{kV}$ sampai $6,3 \mathrm{kV}$.

\subsection{Pemodelan Sistem Kelistrikan}

Pemodelan sistem kelistrikan pabrik Amurea 2 PT. Petrokimia Gresik ini digunakan untuk mengetahui sistem kelistrikan yang eksisting dengan tujuan salah satunya untuk simulasi load flow. Simulasi load flow ini digunakan untuk mengetahui kondisi sistem saat steady-state. Dari analisis aliran daya ini dapat diketahui tegangan bus, pembebanan transformator, pembebanan bus, rugi - rugi daya listrik, factor daya tiap feeder. Setelah dilakukan analisis aliran daya, kemudian dilakukan simulasi short-circuit untuk mengetahui hubung singkat yang terjadi pada pemodelan sistem sehingga dapat melakukan koordinasi proteksi dengan tepat. Berikut ini adalah gambar pemodelan sistem pada pabrik Amurea 2 PT. Petrokimia Gresik yang dapat dilihat pada gambar 3 . 
Volume 16 Nomor 1 (2021) 1-13

E-Link P-ISSN 1858-2109 E-ISSN 2656-5676

Jurnal Teknik Elektro dan Informatika

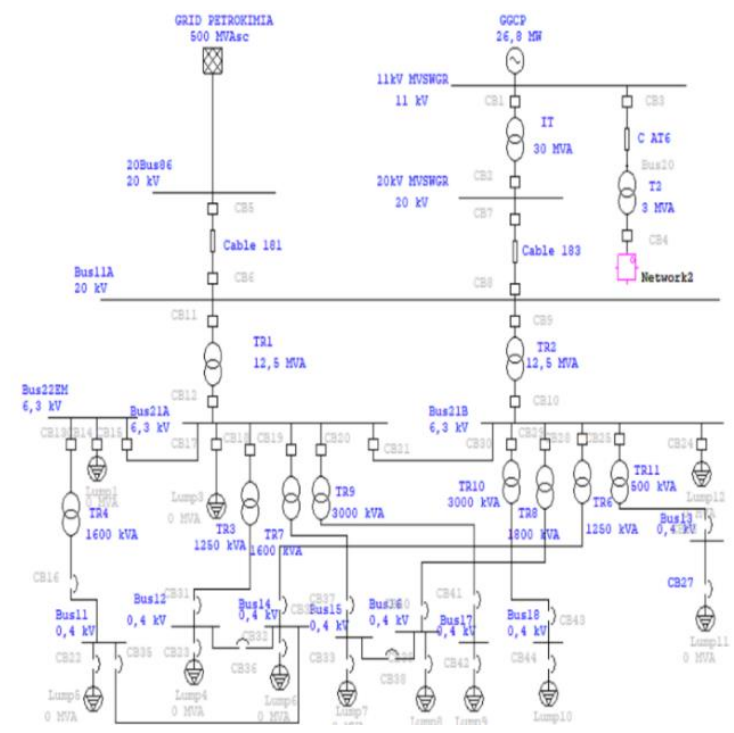

Gambar 3 Single Line Diagram Pabrik

Amurea 2 PT Petrokimia Gresik

\subsection{Simulasi Load Flow}

Simulasi load flow dilakukan untuk selain mengetahui arah laju aliran daya pada sistem juga untuk mengetahui besar arus nominal yang melewati tiap bus dalam keadaan beban maksimum (full load ampere). Dalam menentukan setting relay arus lebih sangat penting untuk mengetahui besarnya arus beban maksimum yang melewati tiap relay. Relay arus lebih tidak boleh bekerja dalam kondisi beban maksimum. Maka dari itu, nilai arus pick up diset lebih besar dari arus beban maksimum. Berikut ini adalah gambar 4 tampilan simulasi load flow pada software ETAP 12.6.

Pada gambar 4 telah dilakukan simulasi load flow dan dapat dilihat bahwa secara umum sistem kelistrikan di pabrik Amurea PT. Petrokimia Gresik dapat dikatakan cukup baik karena hanya terdapat beberapa bus yang berwarna merah muda yaitu artinya bahwa bus tersebut termasuk dalam kondisi marginal yaitu tegangan sistem pada bus tersebut mengalami kondisi under voltage tetapi masih dalam batas standar yang diijinkan. Untuk lebih jelasnya dapat dilakukan analisis sistem kelistrikan pada menu alert view pada simulasi load flow ini untuk melihat kondisi sistem kelistrikan yang mengalami kondisi critical maupun kondisi marginal.

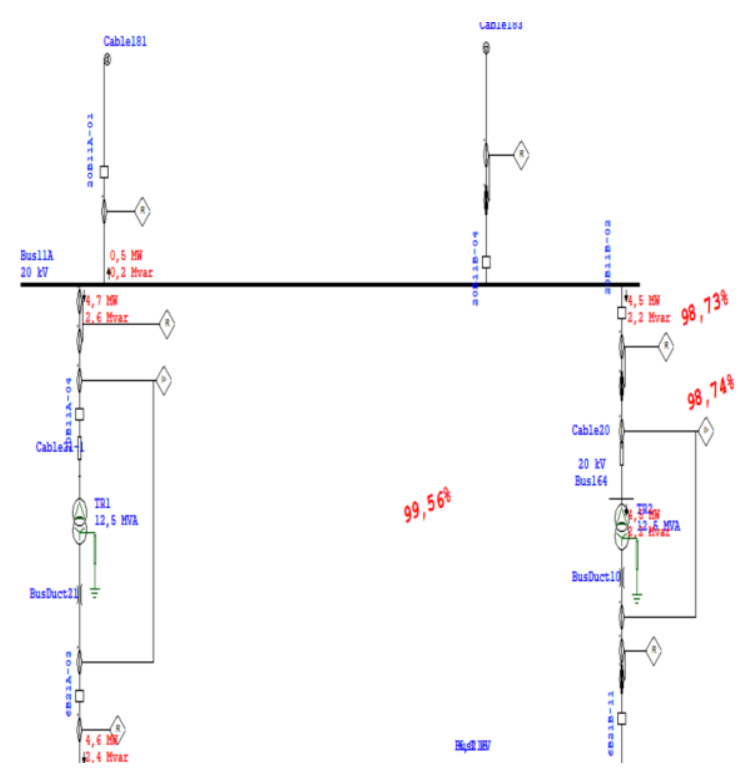

Gambar 4 Tampilan Simulasi Load Flow Software ETAP 12.6

\subsection{Simulasi Short- Circuit}

Simulasi short-circuit adalah simulasi yang digunakan untuk mendapatkan besar nilai arus hubung singkat ketika terjadi gangguan. Analisa hubung singkat ini digunakan untuk menentukan setting relay arus lebih. Untuk perhitungan arus hubung singkat digunakan 2 parameter yaitu hubung singkat maksimum dan hubung singkat minimum. Hubung singkat minimum adalah 
hubung singkat line to line pada saat 30 cycle. Sedangkat hubung singkat maksimum adalah hubung singkat 3 fasa pada saat 4 cycle. Untuk menentukan arus hubung singkat minimum dan maksimum diambil dari arus kontribusi yang menuju ke bus. Berikut ini adalah tampilan simulasi short-circuit pada pabrik Amurea 2 PT. Petrokimia Gresik seperti pada gambar 5 .

\subsection{Setting Koordinasi Proteksi Manual}

Setting koordinasi proteksi menggunakan perhitungan secara manual digunakan sebagai pembanding dengan setting koordinasi proteksi menggunakan algoritma genetika melalui program di software MATLAB R2013a. Secara singkat, setting koordinasi proteksi menggunakan perhitungan manual dilakukan dengan terlebih dahulu menghitung setting low set yang berguna sebagai proteksi sistem ketika terjadi gangguan beban atau overload. Setelah itu, dilanjutkan dengan menghitung setting high set yang berperan sebagai bagian proteksi ketika terjadi hubung singkat. Seringkali hasil plot pada software ETAP 12.6 pada menu star view simulation yang berupa kurva karakteristik relay invers dan instan terjadi overlapping antar kurva yang mengakibatkan koordinasi antar relay tidak bekerja secara maksimal antara relay utama dan relay backup, sehingga perlu dilakukan penggeseran kurva.
4.6. Setting Koordinasi Proteksi Algoritma

\section{Genetika}

Setting koordinasi proteksi menggunakan metode algoritma genetika ini nantinya akan dibandingkan dengan setting koordinasi proteksi menggunakan perhitungan manual. Progam algoritma genetika ini akan dijalankan menggunakan software MATLAB R2013a sebagai algoritma optimasi setting koordinasi relay.

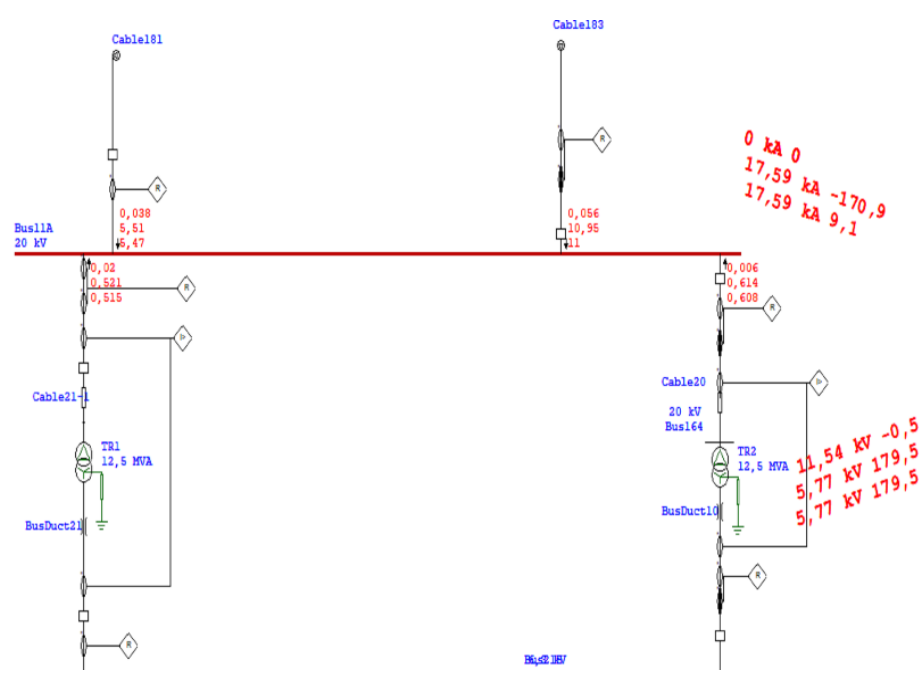

Gambar 5 Hasil simulasi short circuit

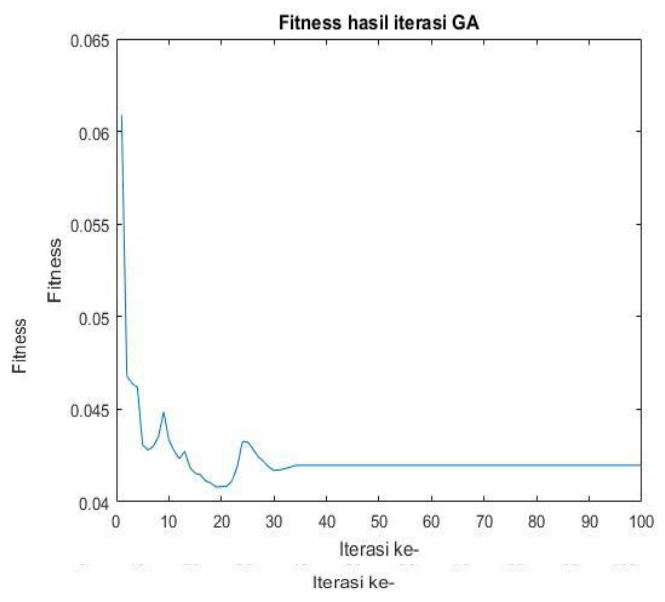

Gambar 6 Grafik Konvergensi Setting Low Set GA 
Volume 16 Nomor 1 (2021) 1-13

E-Link P-ISSN 1858-2109 E-ISSN 2656-5676 Jurnal Teknik Elektro dan Informatika

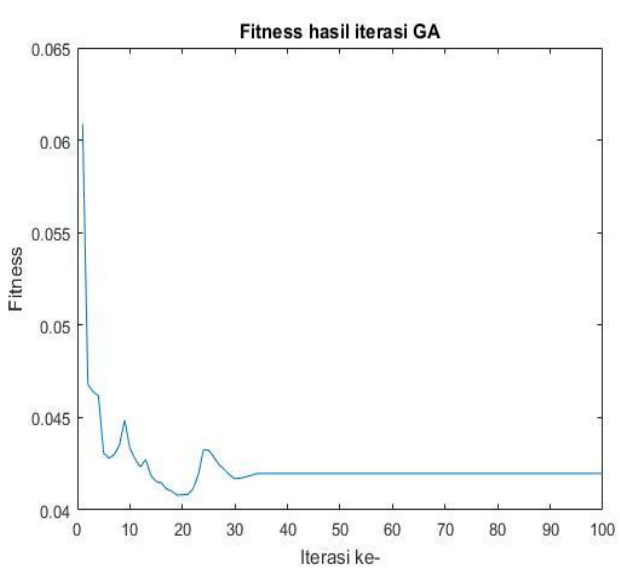

Gambar 7 Grafik Konvergensi Setting High

\section{Set GA}

Gambar grafik 6 dan 7 merupakan perbandingan dari hasil konvergensi hasil GA. Gambar 6 untuk konvergensi setting low set dan gambar 7 setting high set, berupa fitness hasil iterasi algoritma genetika. Terdiri dari sumbu $\mathrm{x}$ adalah iterasi ke (generasi) dan sumbu y adalah nilai fitness.

\subsection{Analisa Data Perbandingan Setting \\ Proteksi}

Setelah dilakukan setting koordinasi relay proteksi arus lebih menggunakan 2 metode yaitu perhitungan secara manual dan metode algoritma genetika. Berdasarkan data yang telah didapatkan akan di input pada software ETAP 12.6 untuk masing - masing relay. Selanjutnya, pada menu "Star Device Coordination" pada tiap tipikal dapat di plot menggunakan menu "Time Current Curve" atau biasa disebut dengan TCC. Kemudian, perbedaan kedua kurva antara menggunakan metode perhitungan secara manual dan algoritma genetika dapat di analisis untuk tiap
- tiap tipikal sehingga didapatkan simpulan hasil setting koordinasi proteksi relay arus lebih yang lebih optimal. Data hasil perbandingan setting proteksi antara menggunakan metode perhitungan manual dan algoritma genetika dapat dilihat pada tabel 2.

Tabel 2 Perbandingan Data Setting Low

Set

\begin{tabular}{|c|c|c|c|c|c|c|}
\hline \multirow[t]{3}{*}{$\begin{array}{l}\text { ID } \\
\text { Relay }\end{array}$} & \multicolumn{3}{|c|}{$\begin{array}{c}\text { Metode Perhitungan } \\
\text { Manual }\end{array}$} & \multicolumn{3}{|c|}{$\begin{array}{c}\text { Metode Algoritma } \\
\text { Genetika }\end{array}$} \\
\hline & \multicolumn{2}{|c|}{$\begin{array}{l}\text { Setting } \\
\text { Lowset }\end{array}$} & \multirow[t]{2}{*}{$\begin{array}{l}\text { Ipu } \\
\text { (A) }\end{array}$} & \multicolumn{2}{|c|}{$\begin{array}{l}\text { Setting } \\
\text { Lowset }\end{array}$} & \multirow[t]{2}{*}{ Ipu (A) } \\
\hline & Tap & $\mathrm{Td}$ & & Tap & $\mathrm{Td}$ & \\
\hline $\begin{array}{l}\text { Relay } \\
76\end{array}$ & 1 & 2,5 & 50 & 2,42 & 3,2 & 121,34 \\
\hline $\begin{array}{l}\text { Relay } \\
18\end{array}$ & 0,8 & 1,6 & 1280 & 0,53 & 3,2 & 862,13 \\
\hline $\begin{array}{l}\text { Relay } \\
11\end{array}$ & 1,2 & 3,2 & 960 & 0,9 & 3,2 & 720 \\
\hline $\begin{array}{l}\text { Relay } \\
3\end{array}$ & 1,14 & 3,2 & 2052 & 1,31 & 0,68 & 2372,2 \\
\hline elay 4 & 1,16 & 5,58 & 2088 & 1,5 & 5,7 & 2700 \\
\hline $\begin{array}{l}\text { Relay } \\
54\end{array}$ & 0,75 & 2,5 & 112,5 & 1,2 & 3,2 & 180,07 \\
\hline $\begin{array}{l}\text { Relay } \\
13\end{array}$ & 0,8 & 1,6 & 400 & 0,55 & 3,2 & 278,55 \\
\hline
\end{tabular}




\section{Analisis Time Current Curve (TCC)}

Dari hasil plot kurva TCC pada 6 tipikal yang telah ditetapkan pada pemilihan tipikal sebelumnya, dapat dilihat pada gambar 8 bahwa setting menggunakan metode perhitungan manual masih belum optimal, karena masih terjadi overlapping unjuk kerja antara relay primer dan backup. Sedangkan, pada gambar 9 dapat dilihat pada setting menggunakan metode GA telah optimal karena tidak ada overlapping unjuk kerja antara relay primer dan backup.

Pada hasil pengujian plot kurva TCC dengan tipikal yang berbeda, dapat dilihat bahwa setiap tipikal terdapat perbedaan antara perhitungan manual maupun dengan menggunakan metode GA. Perbedaan tersebut dapat mempengaruhi dari unjuk kerja dari masing-masing relay.

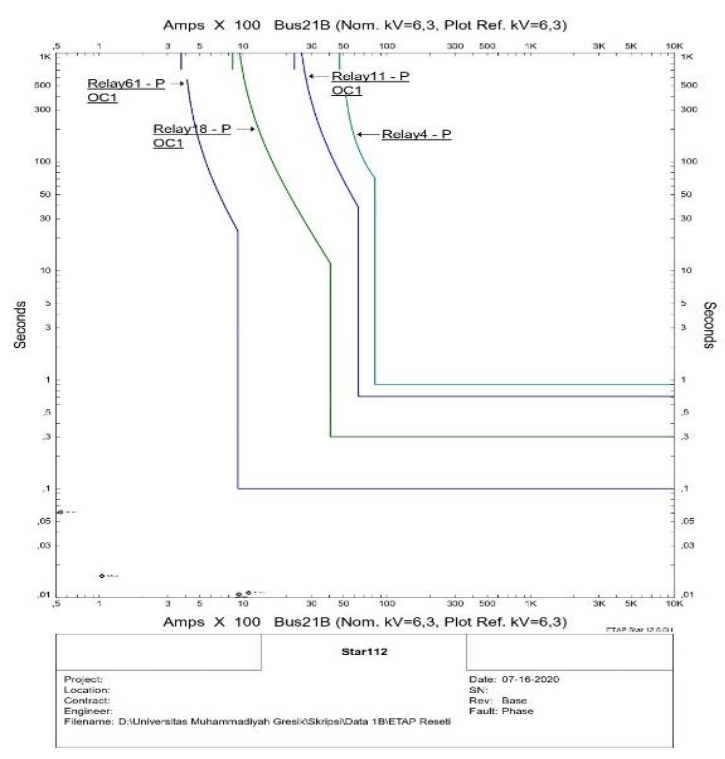

Gambar 8 TCC Perhitungan Manual

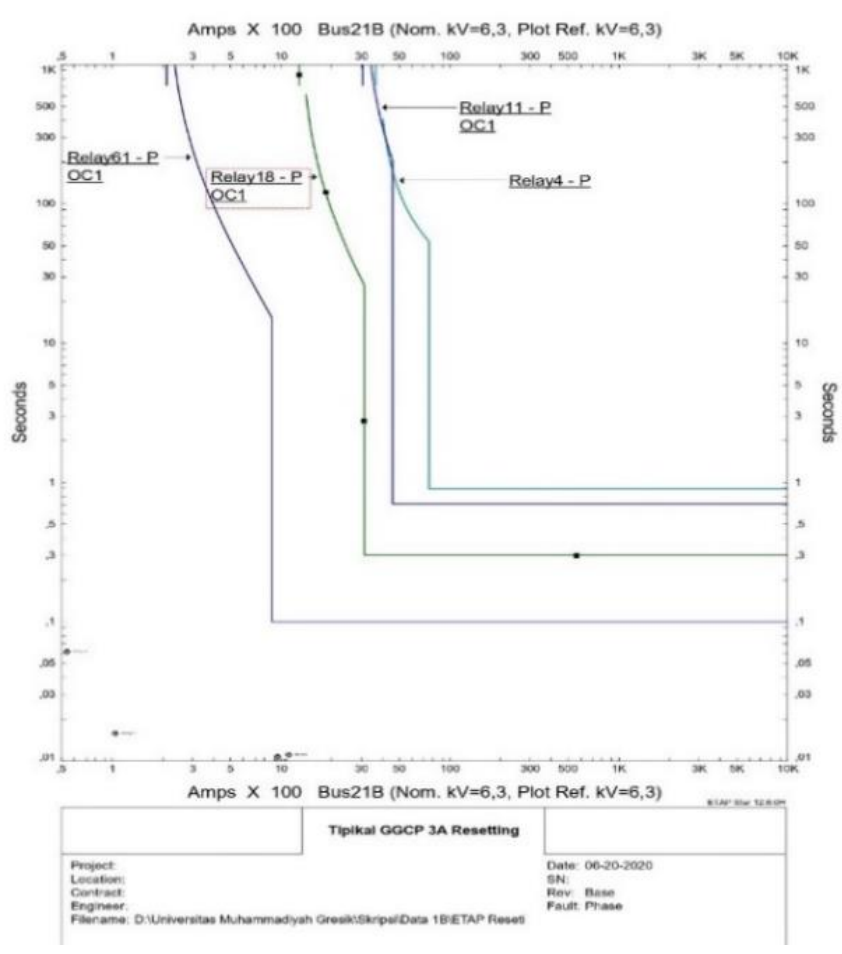

Gambar 9 TCC Tipikal Resetting GA

\section{KESIMPULAN}

Berdasarkan hasil simulasi dan analisa sistem koordinasi proteksi relay arus lebih pada sistem kelistrikan PT. Petrokimia Gresik Pabrik Amurea 2 menggunakan algoritma genetika, dapat diambil beberapa kesimpulan sebagai berikut :

1. Pada simulasi TCC menggunakan metode perhitungan manual masih terjadi overlapping antara relay 11 dan relay 4 .

2. Pada simulasi TCC menggunakan metode algoritma genetika sudah tidak terjadi overlapping antara relay 11 dan relay 4 .

3. Perbedaan margin nilai arus pickup (Ipu) pada perhitungan manual dan metode algoritma merupakan parameter utama penyebab terjadinya perubahan kurva. 
4. Parameter time dial (Td) tidak terjadi perubahan yang signifikan pada perhitungan manual maupun metode algoritma genetika.

5. Perbandingan hasil TCC dengan menggunakan metode algoritma lebih optimal daripada metode perhitungan manual.

\section{DAFTAR PUSTAKA}

[1] Handout Presentation PT. Petrokimia Gresik

[2] Syahputra, Erwin., Pelawi, Zulfadli., Hasibuan, Arnawan, 2018, Analisis Stabilitas Sistem Tenaga Listrik Menggunakan Berbasis Matlab, Jurnal Sistem Informasi ISSN P : 2598-599X; E: 2599-0330 Vol.2 No.2

[3] Tleis, Nasser, 2008, Power Systems Modelling and Fault Analysis, 10.1016/B978-0-7506-8074-5.X5001-2.

[4] Dewangga, Yoga, 2015, Proteksi Adaptif Untuk Koordinasi Optimal Digital Rele Arus Lebih Menggunakan Firefly Algorithm Pada Sistem Distribusi Radial Dengan Pembangkit Tersebar, Surabaya, Institut Teknologi Sepuluh Nopember

[5] Sa'adah, K.S., 2017, Studi Koordinasi Proteksi Pabrik Amurea II PT. Petrokimia Gresik, Surabaya, Institut Teknologi Sepuluh Nopember.
[6] Anderson, M.P., 1998, Power System Protection, Canada, John Willey \& Sons, Inc

[7] Murtopo, A.S., 2015, Analisis Kestabilan Transien dan Koordinasi Proteksi Pada PT. Kaltim Methanol Industri Akibat Integrasi Dengan Sistem 11 kV PT. Kaltim Daya Mandiri, Surabaya, Institut Teknologi Sepuluh Nopember.

[8] IEEE Std 242-2001 ${ }^{\mathrm{TM}}$, 2001, IEEE Recommended Practice for Protection and Coordination of Industrial and Commercial Power System, New York, The Instute of Electrical and Electronics Engineer, Inc., , Ch. 15.

[9] Putra, E.P., 2017, Studi Koordinasi Proteksi Arus Lebih Di PT. Smelting Company Gresik, Surabaya, Institut Teknologi Sepuluh Nopember.

[10] Haupt, L., Haupt, E., 2004, Practical Genetic Algorithm, USA, John Wiley, Ch3.

[11] Siddiq, M.I. , 2015, Simulasi Setting Directional Over Current (DOCR) Menggunakan Algoritma Genetik, Jakarta, Universitas Negeri Jakarta. 